\title{
Comercio de leña en el municipio de Cucaita en la década de 1950
}

Elsa-Yaneth Vanegas-Toba ${ }^{1}$

Fecha de recepción: 2 de octubre de 2020

Fecha de aprobación: 4 de noviembre de 2020

\section{Resumen}

Este artículo aborda, como tema central, el comercio de leña en el municipio de Cucaita en la década de 1950. Tiene como propósito evidenciar el contexto económico, laboral y social de la población y, a la par, el desarrollo de esta actividad económica. Las actividades económicas de la población cucaitense para la época, giraban en torno al sector agrícola, destacándose los cultivos de cereales como el trigo, la cebada y la avena -estos para la zona baja y plana-; en el páramo se destacaba el cultivo de papa y en menor medida el desarrollo de la ganadería. De ahí que paralelo al comercio de la leña se desarrollara también el de otros productos como harinas tostadas, cuchucos, huevos, leche, arepas y quesos. Por lo tanto, el proceso metodológico se desenvuelve desde la historia ambiental, a partir de los testimonios de los pobladores del municipio, quienes manifiestan la importancia de esta actividad económica para atravesar determinadas dificultades económicas; de igual manera, se refiere al impacto ambiental detonado por este tipo de comercio, que todavía persiste en la actualidad.

Palabras clave: animales de carga; alquiler de personas; comercio de leña; necesidades básicas; población.

\footnotetext{
${ }^{1}$ M. Sc. (c). Instituto Técnico Industrial Rafael Reyes (Duitama-Boyacá, Colombia). elsa.vanegas@uptc.edu.co. ORCID: 0000-0002-0520-0509
} 


\section{Firewood Trade in the Cucaita Town at the 1950's}

\section{Abstract}

This article addresses, as a central theme, the firewood trade in the municipality of Cucaita in the 1950s. Its purpose is to show the economic, labor and social context of the population and, at the same time, the development of this economic activity. The economic activities of the Cucaitense population at the time, revolved around the agricultural sector, highlighting cereal crops such as wheat, barley and oats these for the low and flat area-; in the moor, potato cultivation stood out and, to a lesser extent, livestock development. Hence, parallel to the firewood trade, that of other products such as toasted flours, cuchucos, eggs, milk, arepas and cheeses was also developed. Therefore, the methodological process unfolds from environmental history, from the testimonies of the inhabitants of the municipality, who manifest the importance of this economic activity to go through certain economic difficulties; Similarly, it refers to the environmental impact triggered by this type of trade, which still persists today.

Keywords: basic needs; population; renting people; wood trade.

\section{Para citar este artículo:}

Vanegas-Toba, E.-Y. (2020). Comercio de leña en el municipio de Cucaita en la década de 1950. Pensamiento y Acción, 29, 63-82.

Esta obra está bajo licencia internacional Creative Commons Reconocimiento 4.0 


\section{Introducción}

El tema de investigación se relaciona con las actividades económicas existentes en la década de 1950 en el municipio de Cucaita. Al respecto, su economía se ha caracterizado por el desarrollo agrícola; en particular, durante ese periodo, en torno a la producción de cereales como el trigo y la cebada, además de la agricultura y la ganadería. Sin embargo, es necesario analizar otro tipo de actividades igualmente relevantes, pero que no han sido visibilizadas. En ese sentido, el artículo enfatiza que, además de la agricultura y la ganadería, se generaron otros sectores productivos representativos, como el comercio de diferentes productos; entre ellos, de leña.

Durante ese lapso, Cucaita destacaba por la riqueza de su vegetación y sus fuentes hídricas, elementos que brindan información sobre la existencia de un ambiente distinto. Por lo tanto, se analiza cómo el comercio de leña se transformó en la principal actividad para la época, que sirvió para satisfacer las necesidades de la población y, además, detonó algunos de los problemas ambientales que enfrentan sus habitantes en la actualidad.

En ese tenor, la investigación expone que, con el objetivo de cubrir sus necesidades básicas, la población cucaitense comenzó a emplearse en la venta de leña, lo cual se consolidó como actividad económica. En consecuencia, intenta demostrar cómo esta modalidad de comercio permitió a las familias de la época sobrevivir en un contexto difícil respecto de las condiciones laborales predominantes, teniendo en cuenta que en las haciendas -su primordial fuente de empleo- el número de trabajadores contratados para las actividades de siega y trilla de los cereales no era muy alto.

Entre los resultados de la investigación sobresale que los habitantes de Cucaita dedicados al comercio de leña construyeron un sistema económico relacionado con la preparación de cargas de este producto. Según las fuentes primarias, existía un proceso preparativo antes de efectuar la venta de leña, del cual dependían restaurantes, asaderos o panaderías. Así, además de garantizar la cobertura de necesidades básicas, esta actividad contaba con abundante y variada materia prima. 
Respecto de los estudios adelantados sobre este tema, no se encuentran investigaciones en el municipio: los trabajos sobre Cucaita se enfocan en aspectos considerados importantes, como logros y beneficios para la comunidad; en particular, en personajes cucaitenses o en hombres y mujeres que han trazado un camino en la vida religiosa y han despertado el orgullo de los habitantes, pues, a lo largo de su historia, esta población ha destacado como semillero y cuna de devoción. Por otro lado, varias investigaciones han subrayado la labor de personalidades de la gestión pública. En ese sentido, sobresalen las publicaciones de Jerónimo Gil Otálora; en especial, Historias de vida que forjaron un pueblo: Cucaita, dedicado a la descripción del municipio, sus habitantes, sus actividades económicas y la exaltación del papel desempeñado por personajes ilustres. Otro autor relevante es Henry Neiza, quien, en Historia colonial del pueblo de indios de Cucaita: 1556-1819, aborda temas ligados con la configuración social, política, económica y religiosa de Cucaita durante ese periodo.

Por lo tanto, la fuente oral es fundamental para el desarrollo de la investigación, debido a que no existen trabajos previos sobre el comercio de leña y de la necesidad de comprender por qué, en la actualidad, el municipio presenta condiciones ambientales desfavorables, como la falta de agua. A partir de las entrevistas realizadas y de la información obtenida, se analizan cuatro aspectos: población, trabajo, comercio de leña y afectación ambiental. Por ende, en un primer apartado, se describe el aspecto de Cucaita en 1950, en relación con las viviendas, caminos, vegetación y condiciones de vida.

Posteriormente, se enlaza a la población con las actividades económicas y su cotidianidad; se destacan las características sociales, económicas y familiares prevalentes en ese periodo y las relaciones de poder manifestadas dentro de cada grupo, considerando que, a partir de los roles desempeñados por sus integrantes, se trata de una sociedad patriarcal. En cuanto al trabajo, se observa el nivel de ocupación, tanto para adultos como para niños.

Por último, se estudia el comercio de leña como salida a las múltiples dificultades vividas por los habitantes de Cucaita, tejiendo en torno a esta actividad relaciones de dependencia para con un producto; una contrata, un cliente 0 , 
simplemente, un amigo. El comercio de leña significaba, para los cucaitenses, la redención de todas sus necesidades.

Adicionalmente, el tema ambiental se interpreta, a través de la información obtenida, como resultado del impacto negativo que sucede a nivel de la riqueza forestal del municipio; la vegetación disminuyó drásticamente, desatando graves problemas, como escasez de agua y erosión acelerada, factores con los que la población ha tenido que aprender a convivir, aunque numerosas familias han migrado a otras regiones en busca de mejores condiciones para las actividades agrícolas, insertas en la base de la economía familiar de la región.

\section{Metodología}

En la esfera del proceso metodológico, la investigación se enfoca en la historia ambiental, línea que ha comenzado a tomar fuerza debido al deterioro ecológico y los conflictos sociales detonados en torno a los recursos naturales en las décadas de 1970 y 1980, así como los planteamientos de distintos autores, como Nicolo Gligo, Claudia Leal León, Katherinne Mora, Stefania Gallini, Patricia Clare y Giuseppe Feola, entre otros. La investigación se basa principalmente en la fuente oral; al respecto, Mariezkurrena afirma:

Es la especialidad dentro de la ciencia histórica que utiliza, como fuente principal para la reconstrucción del pasado, los testimonios orales; y que retoma las palabras de Paul Thompson al referirse a historia oral como la más nueva y la más antigua forma de hacer historia (2008, p. 227).

El trabajo se apoya en la visita y observación de los lugares que representan un gran valor sentimental para los habitantes de Cucaita. De esta manera, el interés de la investigación se centra en la realización de entrevistas a hombres y mujeres que protagonizaron la historia reciente de Cucaita; se recurrió a la gente común con el objeto de reconstruir aspectos de la cotidianidad urbana y rural. Como muestra demográfica para la ejecución de las entrevistas, se integró un grupo de 30 personas, incluidos hombres y mujeres que vivieron directamente el comercio de leña y que hoy tienen entre 75 y 85 años. 
La fuente oral basada en la entrevista se reforzó con las fuentes documentales localizadas en el Archivo Municipal, el Archivo del Concejo, el Archivo Parroquial, el Archivo Regional de Boyacá, el fondo de investigadores de la Biblioteca Central de la Universidad Pedagógica y Tecnológica de Colombia, la Biblioteca Luis Ángel Arango y, en particular, el periódico Cucaita: Génesis, Luz, Vida y Espigas y los censos de población nacionales y estructurados por departamentos, en los que se discriminan datos por municipio.

\section{Cucaita en la década de 1950}

Cucaita se localiza en la zona occidental de la provincia del Centro del Departamento de Boyacá; su cabecera se ubica a $05^{\circ} 32^{\prime} 45^{\prime \prime}$ de latitud norte y $73^{\circ} 27^{\prime} 26^{\prime \prime}$ de longitud oeste. Limita por el norte con Sora, por el este con Tunja, por el sur con Tunja y Samacá y por el oeste con Samacá.

Geográficamente, se sitúa sobre una altiplanicie en la rama oriental de la Gran Cordillera de los Andes, por lo que cuenta con una diversidad de morfologías, "formada[s] por pequeñas estribaciones, colinas y mesetas con las denominaciones de los Escalones, Piedra Parada o Loma de las Cruces, Alcalá, Peña Negra, el Infiernito y el Alto del Azulejo, rodeadas de bosques milenarios y de vegetación de vistoso colorido" (Angarita, 2010, p. 135). En la Figura 1 se aprecia la división por veredas del municipio.

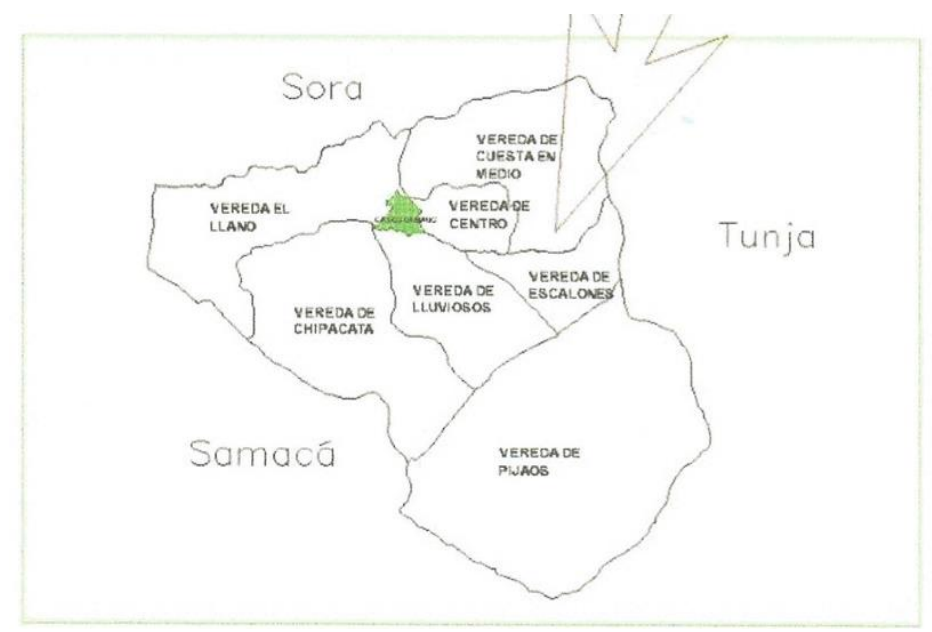

Fig. 1. Mapa de Cucaita y sus veredas.

Fuente: Mapa tomado del Plan de Desarrollo del Municipio de Cucaita Boyacá 2012-2015, p. 20 
En 1950, el pueblo era pequeño: existían pocas viviendas de tapia pisada, pertenecientes a personas importantes, como los dueños de las haciendas y los amplios hatos ganaderos que cuidaban ellos mismos. Algunas casas todavía conservan su aspecto colonial, a pesar de las modificaciones. Estas construcciones se han reemplazado poco a poco por otras de ladrillo y cemento. En las Figuras 2 a 8 se observan viviendas intactas o restauradas para conservar casi completamente su aspecto original.

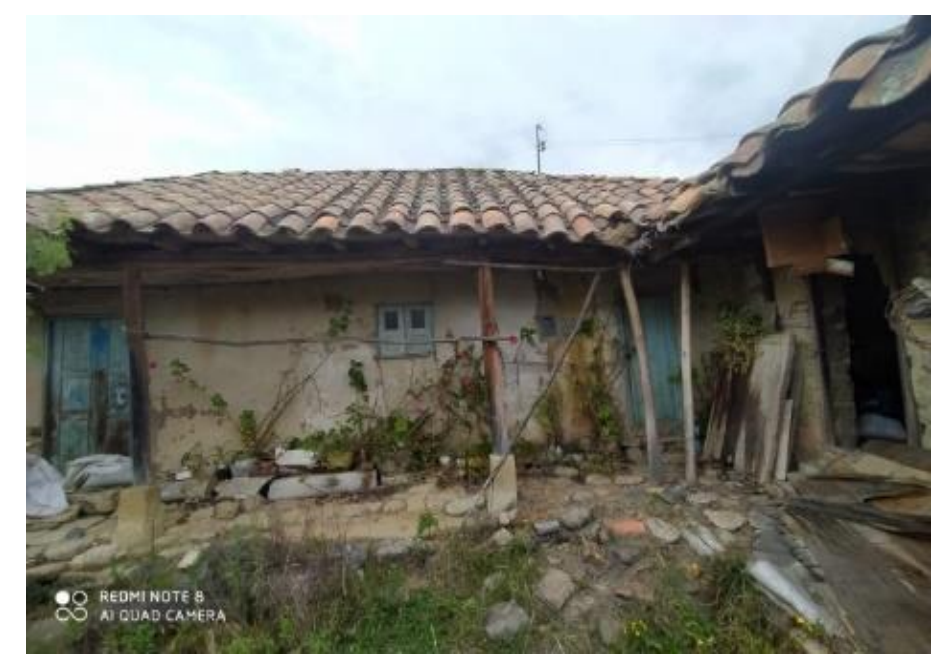

Fig. 2. Vivienda de la década de 1950; se conserva en su estado original.

Fuente: Elsa Vanegas; fotografía tomada el 18 de septiembre de 2020 en la vereda de Lluviosos, municipio de Cucaita
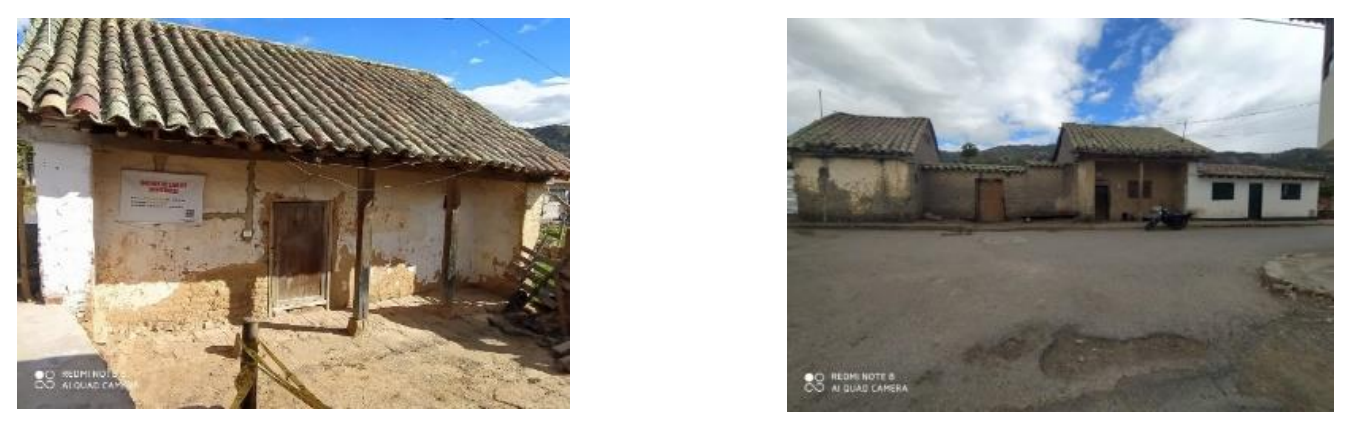

Fig. 3 y 4. Viviendas de la década de 1950.

Fuente: Elsa Vanegas; fotografías tomadas el 18 de septiembre de 2020 en el centro del municipio de Cucaita 


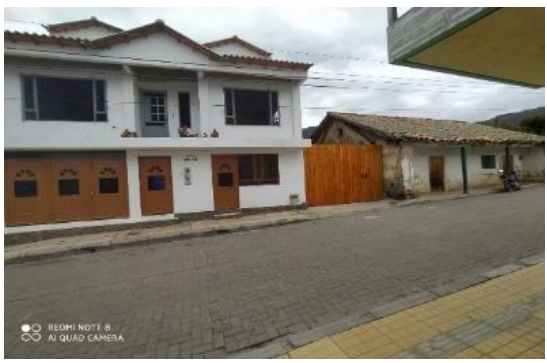

Fig. 5. Vivienda de la década de 1950 y vivienda moderna.

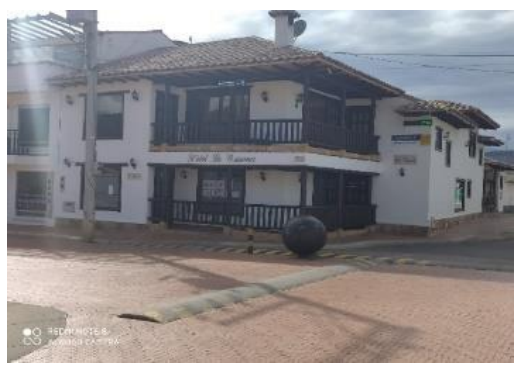

Fig. 6. Vivienda restaurada.

Fuente: Elsa Vanegas; fotografías tomadas el 18 de septiembre de 2020 en el centro del municipio de Cucaita

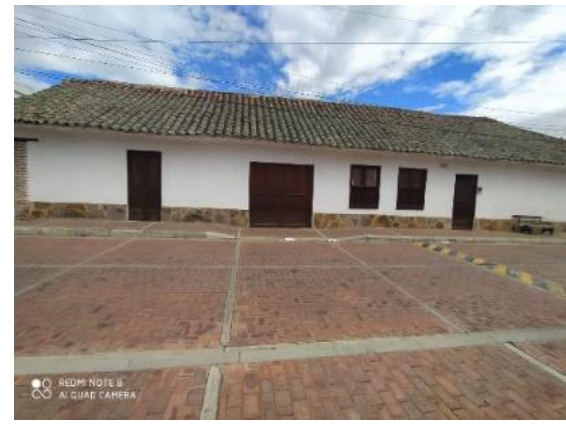

Fig. 7. Vivienda restaurada.

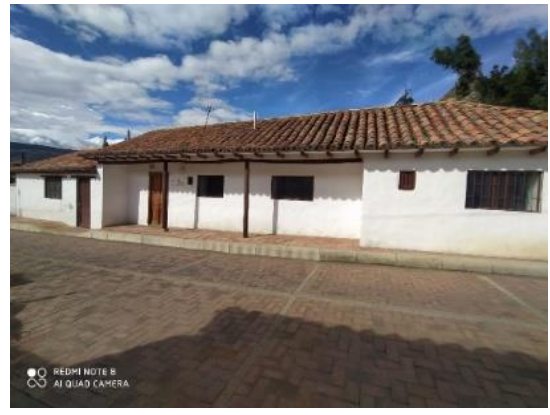

Fig. 8. Vivienda restaurada.

Fuente: Elsa Vanegas; fotografías tomadas el 18 de septiembre de 2020 en el centro del municipio de Cucaita

Las construcciones se elaboraban en bareque. De acuerdo con el señor Víctor, el proceso seguía estos pasos:

Primero, se enterraban palos en dirección vertical simulando el esqueleto de la casita; luego, se amarraban varas por dentro y por fuera en dirección horizontal. Las paredes se cubrían con barro mezclado con el tamo de cebada y trigo y con paja conocida como rabo del zorro y el techo se cubría con paja y ramas. Algunas casitas eran de varias habitaciones, otras de una sola, esto dependía de la posición económica del dueño. Estas construcciones se reforzaban con adobe (V. García, entrevista, 21 septiembre de 2019).

En aquella época, existían caminos relevantes en el municipio. Según la señora Bernarda, "Cucaita era atravesada por dos caminos importantes, por medio de los 
cuales se comunicaba con Tunja, Ráquira, Chiquinquirá, Sáchica y Suta" (B. Vanegas, entrevista, 22 de agosto de 2020). Entre ellos, sobresalía la calle Ráquira, por la cual los forasteros ingresaban con mercancías para venta o intercambio. Estos espacios, de acuerdo con este testimonio, eran de herradura, destapadas, angostas y rodeadas por zanjas por donde circulaba el agua. El otro camino conectaba la calle Ráquira con el poblado en un sector denominado La Toma, hacia las afueras.

Estos senderos constituían el medio de comunicación de esta región de Boyacá con la capital, en la cual se adelantaban importantes actividades comerciales. Por su ubicación, Cucaita era un lugar de paso obligatorio para los ráquiros, quienes vendían productos como loza, sal y leña en la plaza del mercado de Tunja, en donde estas labores adquirían mayor dinamismo. Este grupo provenía de municipios como Sáchica, Sutamarchan, Ráquira y Tinjacá; saliendo del pueblito, subían por la vereda del Escalón, la cual se ubicaba entre límites más cercanos de Tunja con Cucaita. En ese sentido, de acuerdo con el señor Carlos:

Cuando se unían los dos caminos en uno solo, en el sector conocido como La Toma, salían quebrada arriba, por abajo de lo que actualmente es la escuela del pueblo, a dar a donde vive Roberto Buitrago. Tomando hacia arriba por el camino que va para la vereda del Escalón, subían al sector conocido como La Cruz y bajaban a La Virginia, un punto antes de llegar a Las Carrocerías, luego bajaban a la Vuelta del Cangrejo y subían al Alto de San Lázaro, bajando directo a la calle 20 en donde hoy es la Plaza Real: allí funcionó la plaza de mercado. Estaba organizada en varios puntos; por ejemplo, el mercado de la papa era un poco más abajo, en un sector que se conocía como El Hoyo, y el mercado de ganado era en donde hoy funciona el Hospital San Rafael (C. García, entrevista, 21 de septiembre de 2019).

Las anteriores precisiones corresponden a la ruta que seguían quienes transportaban, desde otros municipios, productos para vender o intercambiar por el camino o directamente en la plaza. Se dirigían hacia Tunja con burros, caballos y yuntas de bueyes cargados de mercancía; además, posaban, tomaban el alimento y preparaban al animal para el viaje. En ese sentido, según el señor Alfredo: 
En las pocas casitas que había en Cucaita, varias prestaban el servicio de posada para quienes venían desde Ráquira con mercancía para la venta en Tunja los días de mercado. Se brindaba la posada y se ofrecía la alimentación para las personas y los animales. Los forasteros tendían las enjalmas y dormían sobre ellas; a eso de las dos de la mañana, luego de haber descansado y comido, enjalmaban los burros y seguían su camino hasta llegar a Tunja. Nuestro oficio, como niños, era arrancar la alfalfa, hacer los manojos y tenerlos listos para la venta; con estas plantas, se alimentaban los animales de carga. Los hombres se encargaban de preparar la posada y las mujeres de preparar la merienda, todo era negocio y así se veía la plática, por lo menos, en el pueblo (A. Daza, entrevista, 24 de agosto de 2019).

Los alimentos se cocinaban en los fogones; algunos se ubicaban sobre tarimones de adobe y, otros más, en el piso. "En donde funcionaban las posadas, se utilizaba el tarimón para la preparación de los alimentos, ahí se podían montar con facilidad grandes fondos de comida y era muy rápido que se cocían los alimentos. En las casas de familia, se tenían los fogones en el piso y en ellos se preparaba la alimentación" (M. López, entrevista, 26 de agosto de 2020).

En las Imágenes 9 y 10 se aprecia la estructura de los tarimones, tanto reconstruidos con ladrillo como consistentes con su aspecto original.

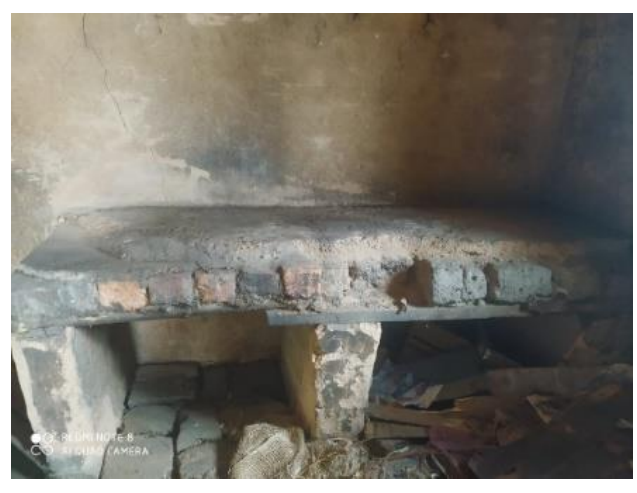

Fig. 9. Tarimón reconstruido

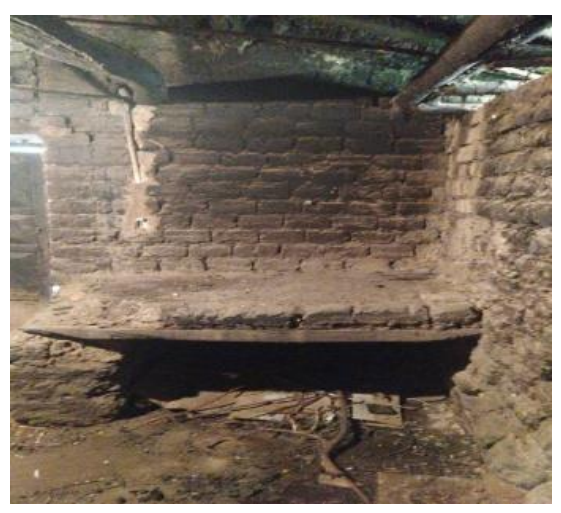

Fig. 10. Cocina y tarimón original

Fuente: Elsa Vanegas; fotografías tomadas el 18 de septiembre de 2020 en las veredas de Lluviosos y Chipacatá, municipio de Cucaita 
Respecto de la indumentaria, la población usaba prendas muy simples, como alpargatas de suela de caucho recubiertas de agonal, similar a la lona, que se usaban para ir a misa; sin embargo, abundaban las personas que carecían de calzado. Los pobladores "utilizaban las mantas, sobre todo, para la elaboración de la ropa interior y los pantalones para los hombres. El vestido era muy sencillo; en el caso de las mujeres, ellas vestían con ropones normales" (G. Gómez, entrevista, 19 de agosto de 2019).

La gente era pobre y pasaba por grandes necesidades. Los pobladores vivían mal alimentados, mal vestidos y, en el caso de las mujeres, sufrían los mayores perjuicios, pues los hombres podían relajarse consumiendo guarapo o chicha en las tiendas, "mientras que las mamás tenían que arreglárselas para darle de comer a sus criaturas; fueron tiempos que, a nivel de familia, duele recordar. Era el tiempo en donde el dicho popular 'soy de la tierra donde muchos nacieron y se criaron pocos' era la presentación de uno" (H. Niño, entrevista, 27 de agosto de 2020).

En el ámbito de la riqueza natural e hídrica, Cucaita era un municipio pletórico en bosques de plantas nativas protectoras de mantos acuíferos. En palabras de la señora Luz Herminda:

La mayor parte de la vegetación de la época era encenillo, arrayán, ruque, raque, mulato y chusque, del cual había bastante y era el apropiado para elaborar las jaulas y los canastos en los que se cargaban huevos, quesos, cuajadas y arepas. Otras plantas eran cañuela, romero, chocos y fucsias. En el pantano, abundaban la cortadera, esparto, cardón, piñuela y árnica. En la parte alta, alcancé a conocer el frailejón, que perduró hasta mediados de 1970. Después de que se talaron los bosques, el agua empezó a escasear, llegando a ser uno de los problemas medioambientales más graves que enfrenta nuestro municipio $(H$. Niño, entrevista, 27 de agosto de 2020).

En algunas zonas del municipio, especialmente en la parte alta, florecía una abundante vegetación. Posiblemente, su erradicación se relaciona con los severos problemas de escasez de agua que se presentan en la actualidad. 


\section{Población de Cucaita en 1951. Actividades económicas y cotidianidad}

En 1950, el comercio de leña se vivía con una enorme intensidad. De acuerdo con el Censo Nacional de Población del 9 de mayo de 1951, Cucaita registraba, como municipio adscrito al Departamento de Boyacá, un total general de población de 1,875 habitantes, de los cuales 935 eran hombres y 940 eran mujeres. En la cabecera municipal, habitaban 346 personas, de las cuales 169 eran hombres y 177 eran mujeres, mientras que en el área rural había 1,529 habitantes: 766 hombres y 763 mujeres (DANE, 1951, p. 11).

Es importante subrayar que Cucaita se ha caracterizado por el desarrollo de una economía que gira en torno a la agricultura y la ganadería, aspectos que explicaban la concentración de la población en el área rural, a diferencia de la zona urbana, primordialmente enfocada en el aspecto comercial, con tiendas de guarapo, chicha, sal, panela, miel, pan y algunos granos. En el casco urbano, también funcionaban las posadas, que generaban ingresos adicionales a los propietarios de las viviendas.

En la Figura 11, se analiza la distribución demográfica en los sectores rurales y urbanos. Del total de la población pormenorizado en párrafos precedentes, el 18\% vivía en el área urbana del municipio, dedicado a las actividades comerciales previamente citadas; en tanto, el $82 \%$ habitaba en las zonas rurales y se desempeñaba en la agricultura, ganadería, cuidado de rebaños, elaboración de quesos, tostado de cebada y trigo para molienda y venta y preparación de cargas de leña para venta e intercambio por otros productos, como panela y miel:

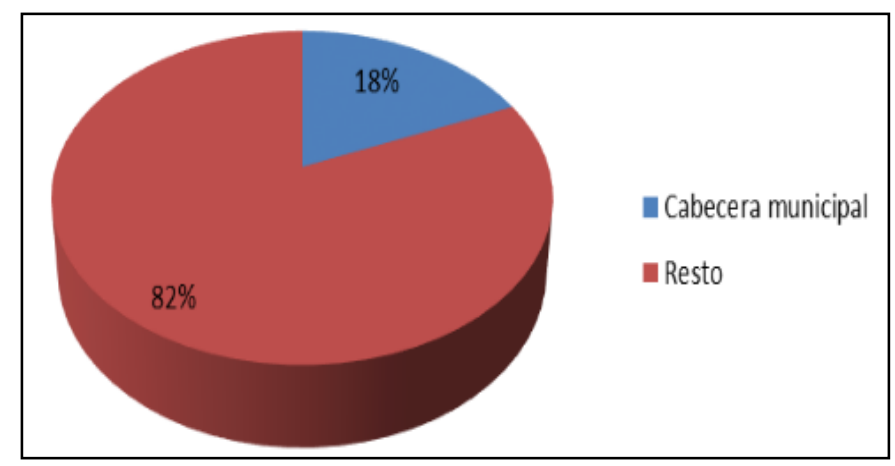

Fig. 11. Distribución demográfica en Cucaita según el Censo Nacional de Población de 1951 
Asimismo, se observa que el número de hombres y de mujeres en el sector rural era casi equivalente, pues únicamente había 3 hombres más por encima de la cifra total de mujeres para la época.

La población de Cucaita desarrollaba actividades agrícolas y ganaderas, como el cultivo de maíz, papa, nabos, calabaza y arveja; algunos de ellos se sembraban en huertas y en muy pequeñas cantidades, más enfocadas al consumo familiar que al comercio. La venta de trigo y cebada tostada era una actividad económica común; en particular, los hombres dedicaban el día completo a tostar y moler el cereal, empacarlo en bolsas y porcionarlo adecuadamente; después, el día de mercado, preparaban los animales de carga para salir temprano y vender su producto en la plaza. Las mujeres se encargaban de elaborar quesos, arepas y cuajadas con el mismo propósito. Como explica la señora Bernarda:

En la casa, mi papá era el que se encargaba de tostar la granza, molerla y empacarla en bolsitas para vender el cuchuco en la plaza, cargaba el burro y salía con su carga para Tunja. Mi mamá se encargaba de hacer los quesos, la cuajada y las arepas de maíz, ella también preparaba su maleta y en un burro o a la espalda llevaba sus cositas a la plaza. A mí me correspondía la recolección y venta de los huevos, ya tenía lista la jaula donde los guardaba cuidando que no se vencieran para cargarlos a la espalda y llevar a Tunja. Mis hermanos menores se quedaban en la casa cuidando del ganado y las gallinas, adelantando los oficios de la huerta y el almuerzo (B. Vanegas, entrevista, 22 de agosto de 2020).

La mayor parte de los habitantes del municipio se trasladaban a Tunja los días de mercado para vender los productos alistados con anterioridad. Por otro lado, durante aquella época, el empleo de mano de obra en las haciendas era otra fuente de trabajo asegurado para los dueños de las cosechas, pero no para los jornaleros, quienes recibían maltratos y desprecios al pedir espacios para trabajar. Muy pocos lo lograban.

Además de la agricultura, también se adelantaban los oficios relacionados con el cuidado del ganado y el pastoreo de ovejas, en los que se empleaba a los 
niños. Algunos testimonios relatan que, desde los 10 años, los niños se empleaban en las haciendas para ello (V. García, entrevista, 21 de septiembre de 2019).

Pero quizá la actividad más importante y segura para la población de la época consistía en la selección, tala, secado y venta de leña, en la cual se empleaban una cantidad considerable de personas, pues la agricultura y la ganadería no se practicaban a gran escala y la demanda laboral en las haciendas no era alta.

\section{Comercio de leña}

Como se ha mencionado, el comercio de leña fue una de las actividades más sobresalientes, primordiales y seguras para la población de Cucaita en la década de 1950. Según el Plan de Desarrollo de Cucaita del periodo 2012-2015, la mayor parte del suelo sigue dedicándose a las actividades agrícolas y ganaderas, sin tomar en cuenta el comercio de leña, cuyo mayor auge se registró en el citado decenio.

De acuerdo con la información proporcionada por los habitantes, la existencia de una amplia variedad de vegetación, el escaso trabajo en algunas temporadas, las humillaciones recibidas en las haciendas y las necesidades de vestido y alimentación los obligaron a tomar medidas para evitar morir de hambre o frío. De esta manera, muchas personas, incluso niños, vieron como solución a sus problemas el transporte de leña hacia Tunja. Cuando los animales de carga no eran suficientes, hombres, mujeres y niños se alquilaban para cargar a su espalda los tercios, como se documenta en este testimonio:

La situación económica era muy difícil; en ese tiempo, se vivía obligatoriamente de la venta de leña. Para no morir de hambre y viendo lo bueno que era el mercado de leña y que esta abundaba en nuestro municipio, optamos por trabajar ahí. Las personas que contaban con animales de carga acomodaban los tercios y se iban de madrugada para la capital. Cuando les hacían falta animales para cargar, contrataban a varias personas, para que cada una llevara sobre su espalda la maleta (E. Niño, entrevista, 14 de septiembre de 2019).

El comercio de leña requería de un proceso para la preparación de las cargas, además del cumplimiento de exigencias sobre su aspecto: "el cliente exigía que la leña llegara seca, que prendiera con fuerza, que estuviera bien pesada y que 
no estuviera verde. Si no se cumplía con estos requisitos, no nos volvería a comprar y eso nos afectaba directamente; estábamos arriesgando la comida de nuestros hijos" (V. García, entrevista, 21 de septiembre de 2019).

Además, la preparación de la carga de leña tenía en cuenta algunos pasos clave para agilizar el comercio y asegurar una posible contrata; no se podía cortar a la ligera cualquier planta, tampoco se podía hacer a cualquier hora y en cualquier momento. Al respecto, existe este testimonio:

Para cumplir con las exigencias de quienes compraban la leña, se tenían en cuenta varios momentos. Primero que todo, se seleccionaba la planta por cortar, porque tenía que estar seca; es decir, no tener raíz viva. Luego, se cortaba con hacha. Como era una época de lluvias constantes, se ponía a secar, ya que mojada no era fácil venderla. Se hacían los tercios en aros de alambre, se prensaba bien y, finalmente, se cargaba el tercio en bestias o a la espalda de la persona para llevar a vender en Tunja. Esta actividad era considerada como la vaca de leche de las familias en aquel tiempo, de ahí se veían los recursos para mejorar nuestra alimentación (E. Niño, entrevista, 14 de septiembre de 2019).

El comercio de leña fue una actividad económica tan relevante que, incluso, se hacían viajes a Tunja diariamente, como se explica en este testimonio:

Todos los días se caminaba a Tunja, de aquí para allá se llevaban leña, queso, cuchucos, huevos y pollos a la espalda y de allá para acá se traían sal, miel y panela para el mismo pueblo o para Ráquira, Suta y todos esos pueblitos de abajo. El dinero que se reunía era para la manutención de las familias.

La gente también se alquilaba para cargar loza y sal. Cuando los forasteros llegaban a Cucaita y cambiaban productos por leña, acomodaban esas cargas sobre los animales y descargaban la loza, que era llevada en las espaldas de las personas para asegurar que llegara bien a Tunja. En esa época, las lluvias eran constantes y los caminos eran pesados. Los animales se enterraban y caían. Para evitar que se dañara la carga de loza, preferían contratar gente para que ellos, con más cuidado, la llevaran a Tunja. En los 
burros cargaban la leña. Si el animal se enterraba o se caía, a los palos no les pasaba nada, mientras que, si estaba cargado con loza, esta se perdía completamente.

Para llevar las cargas a Tunja, las personas se ponían una cincha en la frente y otra en el pecho, así se aseguraba bien. Cargaban hasta un peso de 4 arrobas y hacían varios descansos hasta llegar a la plaza de mercado (V. García, entrevista, 21 de septiembre de 2019).

Para el transporte de la carga, se empleaban bueyes, por considerarse fuertes y resistentes. Por lo demás, la leña se intercambiaba constantemente por alimento o loza o se vendía a las personas que salían desde Ráquira y los pueblos aledaños. Así lo recuerdan los pobladores que vivieron esta época:

Cuando los ráquiros llegaban al pueblo, además de tener preparada la posada y el alimento, también se tenían listas las cargas de leña. Algunos ya tenían sus contratas $\mathrm{y}$, por cada tercio, ganaban 5 centavos; otros, lo intercambiaban por cazuelas, ollas de barro en las que se preparaban los alimentos, chicha, guarapo, pitos o algo de mercado. Esto evitaba la caminada hasta Tunja y era un buen espacio para acceder a otro producto de necesidad (V. Otálora, entrevista, 16 de marzo de 2019).

De acuerdo con la información y los recuerdos que permanecen en la memoria de la población, la tala y la preparación de cargas de leña también prevalecían en otros municipios más allá de Cucaita, como aparece en este testimonio:

Desde Ráquira, la Candelaria, Sáchica, Suta y Chiquinquirá, los forasteros ya traían tercios de leña, además de loza, ollas, chorotes, cazuelas y pepas como la guayaba; mercancía muy bien envuelta en paja y acomodada en bultos que simulaban un gran balón, que eran cargados hasta Tunja para vender (B. Vanegas, entrevista, 22 de agosto de 2020).

El comercio de leña formaba parte de la cotidianidad de la población. Quienes se dedicaban a esta actividad ofrecían las cargas en panaderías, restaurantes y asaderos de carne, entre otros negocios:

Desde la vereda del Escalón, todos los días, a eso de la una y media de la madrugada, salíamos un grupo de diez a quince muchachos, hombres y 
mujeres, llevando a nuestras espaldas tercios de leña, cebada y trigo tostado para las sopas, harinas, quesos y huevos en jaulas de chusque. Nuestro medio de transporte eran las piernas, todo se hacía a pie. Nos iba mejor al llegar a las panaderías y restaurantes; casi que ahí nos compraban todo y nos hacían las contratas para los demás días. Era un medio seguro para ganar algo y comprar en el mercado, aunque las jornadas de camino eran muy duras: tres horas de ida y tres de regreso, sin zapatos y todo el camino abrigados por la lluvia. Además de nosotros también iba gente mayor, con sus cinco y hasta ocho mulas o burros cargados $(\mathrm{H}$. Niño, entrevista, $27 \mathrm{de}$ agosto de 2020).

El comercio de leña era libre, incluido en el mismo pueblo; se realizaban contratas, sobre todo, para las haciendas, en donde se necesitaba leña para preparar los alimentos de quienes trabajaban allí.

Según la información recolectada, la planta seca más apetecida para vender como leña era el encenillo, que se rajaba con hacha y se ponía a secar al rayo del sol; luego, se prensaba y se cinchaba con alambre sobre el animal. Por un tercio de esta planta se pagaban dos centavos, actualmente equivalentes a unos $\$ 4,000.00$. Al lado del comercio de leña, también estaba el comercio de abono negro, empleado en grandes cantidades para la siembra de papa. Otras plantas muy estimadas en esta actividad comercial eran el rin y el ayuelo:

En las panaderías gustaba mucho el rin, por ser una planta gruesa y dura que no se quemaba tan rápido y guardaba buena brasa; algunos decían que duraba más. Mientras, maderas como el ayuelo se consumían más fácil y rápido, pero era el apetecido en los asaderos de carne y los restaurantes por lo delgada (M. López, entrevista, 26 de agosto de 2020).

De esta manera, la actividad extractiva que representaba el comercio de leña generó la pérdida de la vegetación nativa del municipio, en respuesta, principalmente, a las dificultades económicas por las cuales atravesaban sus habitantes:

Destruían la vegetación buscando recoger leña y llevarla a vender a Tunja; se veían obligados por la situación económica que se vivía en los hogares. Se 
tumbaba mucho monte buscando recursos para comer. Calculo que se perdió un $40 \%$ de la vegetación nativa en la vereda a causa del comercio de leña y la ampliación de terrenos para cultivar (G. Gómez, entrevista, 19 de agosto de 2019).

Era tan normal esta actividad que "en la plaza del mercado había un lugar ya señalado para quienes la vendían; era un comercio normal, sin ningún tipo de control ni restricción" (C. García, entrevista, 21 de septiembre de 2019). De esta manera, la ausencia de controles para la tala y la venta de leña generó graves problemas medioambientales. Aunque este trabajo se centra en Cucaita, en otros municipios cercanos se observa un impacto similar.

Los cálculos se realizaron partiendo del recuerdo de la población sobre la cantidad de vegetación existente en 1950; es decir, se trata de datos imposibles de comparar con otro tipo de información relacionada porque no existe. La aproximación de los cálculos refleja que cerca del $25 \%$ del total de la vegetación nativa se perdió a causa del comercio de leña y la ampliación de los terrenos de cultivo a la orilla del monte.

\section{Conclusiones}

El comercio de leña fue una actividad económica de gran importancia para los habitantes de Cucaita; su abordaje indica las principales razones por las que se deforestó buena parte de la vegetación nativa.

La información recopilada por medio de los diálogos sostenidos con los habitantes del municipio y de las veredas, así como las anécdotas que recuerdan, confirman que todas las plantas eran generadoras de importantes fuentes de agua; sobre todo, el chusque. En el municipio abundaba este recurso y la cantidad de vegetación para la época favorecía y permitía las constantes lluvias; además, la existencia de quebradas, el verde de sus terrenos y el fresco que se respiraba, plantean la existencia de condiciones ambientales diferentes a las que existen actualmente. Fueron tiempos que la población recuerda con nostalgia. 


\section{Agradecimientos}

Agradecimiento a los pobladores de Cucaita que colaboraron con esta investigación

y que son voz fundamental para comprender los problemas presentes en el municipio.

\section{Referencias}

Alcaldía de Cucaita (2012), Plan de Desarrollo Cucaita-Boyacá 2012-2015, Alcaldía de Cucaita, Cucaita.

Departamento Administrativo Nacional de Estadística (1951), Censo Nacional de Población, 9 de mayo de 1951, Multilith-Estadinal, Bogotá.

Gil Otálora, J. (2003), Historias de vida que forjaron un pueblo: Cucaita, Jotamar, Tunja.

Jaime Angarita, C. y Gómez Gómez, P. (2018), Enciclopedia interactiva, turística y cultural de Boyacá, Búhos Editores, Tunja.

Neiza Rodríguez, H. (2018), Historia colonial del pueblo de indios de Cucaita 1556-1819, Corporación Cultural Alejandría, Tunja.

Mariezkurrena, D. (2008), "La historia oral como método de investigación histórica", en Gerónimo de Uztariz, núm. 23-24, Instituto Gerónimo de Uztariz, Pamplona.

\section{Entrevistas}

Daza Acosta, Alfredo, Entrevista personal, 24 de agosto de 2019.

García Buitrago, Carlos Eduardo, Entrevista personal, 21 de septiembre de 2019.

García Chavarría, Víctor Manuel, Entrevista personal, 21 de septiembre de 2019.

Gómez Morales, José Gustavo, Entrevista personal, 19 de agosto de 2019.

López, María Estrella, Entrevista personal, 26 de agosto de 2020.

Niño Niño, Luz Herminda, Entrevista personal, 27 de agosto de 2020.

Niño Alba, Eccehomo, Entrevista personal, 14 de septiembre de 2019.

Otálora, Victoria, Entrevista personal, 16 de marzo de 2019.

Vanegas Miguez, Bernarda, Entrevista personal, 22 agosto de 2020. 